\title{
Comparison of the fracture resistance of dental implants with different abutment taper angles
}

\section{Abstract}

To investigate the effects of abutment taper angles on the fracture strength of dental implants with TIS (taper integrated screwed-in) connection. Thirty prototype cylindrical titanium alloy 5.0mm-diameter dental implants with different TIS-connection designs were divided into six groups and tested for their fracture strength, using a universal testing machine. These groups consisted of combinations of 3.5 and $4.0 \mathrm{~mm}$ abutment diameter, each with taper angles of $6^{\circ}, 8^{\circ}$ or $10^{\circ}$. 3-Dimensional finite element analysis (FEA) was also used to analyze stress states at implant-abutment connection areas. In general, the mechanical tests found an increasing trend of implant fracture forces as the taper angle enlarged. When the abutment diameter was $3.5 \mathrm{~mm}$, the mean fracture forces for $8^{\circ}$ and $10^{\circ}$ taper groups were $1638.9 \mathrm{~N} \pm 20.3$ and $1577.1 \mathrm{~N} \pm 103.2$, respectively, both larger than that for $6^{\circ}$ taper group of $1475.0 \mathrm{~N} \pm 24.4$, with the largest increasing rate of $11.1 \%$. Furthermore, the difference between $8^{\circ}$ and $6^{\circ}$ taper groups was significant, based on the Tamhane's multiple comparison test $(P<0.05)$. In 4.0mm-diameter abutment groups, as the taper angle was enlarged from $6^{\circ}$ to $8^{\circ}$ and $10^{\circ}$, the mean fracture value was increased from $1066.7 \mathrm{~N} \pm 56.1$ to $1241.4 \mathrm{~N} \pm 6.4$ and $1419.3 \mathrm{~N} \pm 20.0$, with the largest increasing rate of $33.1 \%$, and the differences among the three groups were significant $(P<0.05)$. The FEA results showed that stress values varied in implants with different abutment taper angles and supported the findings of the static tests. In conclusion, increases of the abutment taper angle could significantly increase implant fracture resistance in most cases established in the study, which is due to the increased implant wall thickness in the connection part resulted from the taper angle enlargement. 
The increasing effects were notable when thin implant wall was present to accommodate wide abutments.

\section{Keywords}

Dental implants; static compression test; fracture resistance; implant-abutment connection; taper angle; finite element analysis

\section{Introduction}

Most osseointegrated dental implant systems are composed of an endosteal fixture, a component inserted into the jaw bone, and an abutment, connecting the fixture to support or retain the prosthetic superstructure. The abutment is secured to the fixture with a mechanical attachment method and is named the implant-abutment connection. At present, there are a number of implant-abutment connection designs offered by implant companies. They may be classified as either externally or internally connected.

The external hexagonal interface of the original design of Brånemark system, which is a typical external design, has been in use the longest and has functioned well over the years. Recently, it has been incorporated in a number of competing systems. However, the connection has the mechanical disadvantages of exposing implant-abutment interface and abutment screw to greater external loads and bending moments, which can lead to screw joint opening and screw loosening $[1,2]$. Zarb and Schmitt reported clinical outcome of 274 Brånemark implants with the external connection, and they noted 9 abutment fractures and 53 gold screw fractures over a 4 to 9 -year period [3]. In their one-year follow-up study, Jemt et al. reported the overall success rate was $98.6 \%$ for the Brånemark implants, with the most common complications related to loosening gold screws and esthetic complaints[4]. Moreover, problems of screw loosening or fracture are more likely to occur when external connection 
implants are used to support single-unit restorations, where implants are not splinted and are subjected to multidirectional loading that challenges the external connection components and restoration structural integrity. In a multicenter prospective study on external connection implants for single tooth replacement, the most obvious problem experienced during the first year was related to loosening abutment screws with an incidence of $26 \%$ [5]. Becker and colleagues found that retaining screws loosened in 8 of 24 implants restoring single molars with follow-up of 24 months [6].

Since the 1990s, several modifications of the design of external abutment screw, the material of the screw itself and the coefficient of friction between the mated surfaces, have been made to reduce the connection complications. However, mechanical complications of external connections are not eliminated and still remain a concern in the implant community. In order to overcome the connection problems, a new concept of internal connection was developed. Contrary to the external connection, the internal connection design has a feature that extends inferior to the coronal portion of the implant and is located inside the implant body. The internal connection has a mechanical advantage of dramatically reducing screw failures by distributing occlusal forces deep into the implant and shielding the abutment retention screw from excess loading. Further, deep joints in internal connections are more likely to resist bending forces than shallow joints in external connections. Therefore, internal connections have superior joint strength than that of external counterparts [7].

Of various internal connections, the taper integrated screwed-in (TIS) abutment is becoming more popular, which uses simultaneously a screw and a tapered fit to provide mechanical stability. The TIS-type connection offers high resistance to loosening torques, and it has been reported that loosening of the abutment is prevented [8]. Bozkaya and Müftü analyzed the mechanical properties of the TIS-type connection, with the focus on connection stability parameters of tightening and loosening 
torques [9]. They developed analytical formulas to predict tightening and loosening torque values by combining the equations related to the tapered interface with screw mechanics equations. They found the value of the coefficient of frictions, taper angles, connection depth and outer radius of the implant were the factors affecting implant-abutment connection stability.

It has been well documented that the implant-abutment connection is the weakest part in terms of the whole implant mechanical strength, especially for the internal connection designs which have thin fixture wall thickness at the connecting parts [10]. As for the TIS-type connection, those abovementioned connection parameters can also affect its mechanical strength. Nowadays, different taper angles have been used by different manufacturers in their TIS-type implants. However, there is only limited information can be found in the literature about the relationship between taper angles and the mechanical strength of implants. The purpose of the present in vitro research was to compare the compressive fracture strength of dental implants with different abutment taper angles. In addition to the experimental tests, 3-dimensional finite element analysis (3D-FEA) was carried out to evaluate the stress state of implant-abutment connection areas as a function of different abutment taper angles.

\section{Material and methods}

\subsection{Sample preparation for mechanical tests}

For this in vitro investigation, thirty prototype cylindrical titanium alloy (Ti-6Al-4V) implants divided into six groups $(n=5)$ were fabricated using a BUMOTEC S-191 V (Bumotec SA, Switzerland) CNC (computer numerical control) machining center. The manufacturing dimensional tolerances were set to $10 \mu \mathrm{m}$. To the best of the authors' knowledge, this accuracy tolerance level should be sufficient to satisfy the testing requirements for the present study [11].

\subsection{Overview of implant specimen designs}

The TIS-type dental implant specimens used in this study can be divided into three parts: implant 
body, abutment, and the restorative part. The latter two parts were simplified into one section of superstructure. The implant body had a diameter of $5.0 \mathrm{~mm}$ and length of $13.0 \mathrm{~mm}$. It consisted of two parts: the $2.0 \mathrm{~mm}$-height of non-threaded highly polished cylindrical neck and an $11.0 \mathrm{~mm}$-height of threaded part. The threaded part featured a triangular thread design with a uniform $0.3 \mathrm{~mm}$ thread depth and $0.6 \mathrm{~mm}$ thread pitch. The superstructure part started from the TIS abutment and gradually widened to be the coronal restorative part, which was simplified into a combination of a cylinder (4.5mm-diameter, 5.5mm-height) and a hemispherical dome (Fig.1). Two different abutment diameters, $3.5 \mathrm{~mm}$ and $4.0 \mathrm{~mm}$, at the implant platform level were designed. The abutment connection part had a depth of $3.0 \mathrm{~mm}$ and taper angles of $6^{\circ}, 8^{\circ}$ and $10^{\circ}$. For the purpose of brevity, each specimen was named by two hyphenated numbers, representing the abutment diameter and taper angle, respectively. Thus 5.0mm-diameter implants had names of 3.5-6, 3.5-8, 3.5-10, 4-6, 4-8, and 4-10, respectively.

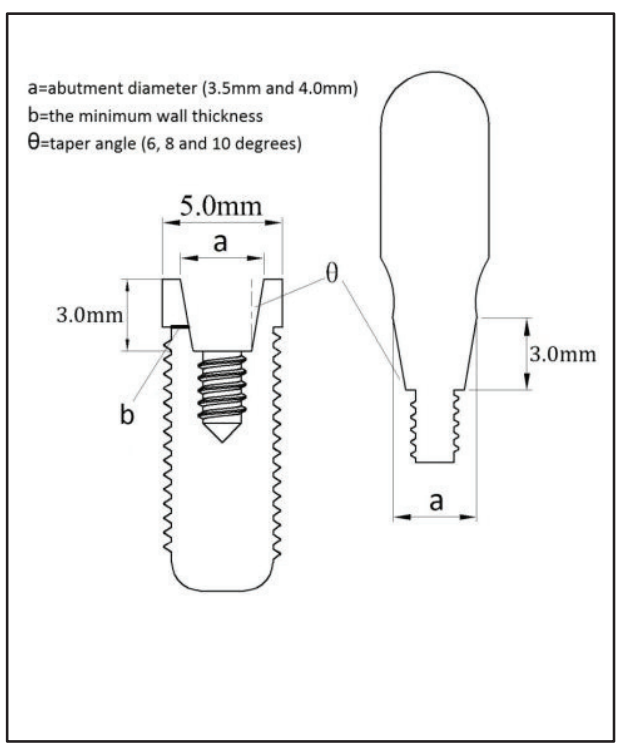

Figure 1 The engineering drawing of the implant specimens tested in this study

\subsection{Overview of the static test set-up}

The implant specimens were investigated in a test setup fabricated according to the ISO 14801 static testing standard (Fig.2). The implants were embedded and secured in a custom jig, which was made up of an aluminum alloy cylinder and a stainless steel block. An internal threaded hole in the depth of 
$10 \mathrm{~mm}$ was cut in the center of the aluminum alloy cylinder to accommodate test implants, and the stainless steel block functioned as a holder for the aluminum alloy cylinder. Implants were inserted into the threaded hole to a depth of $10 \mathrm{~mm}$ in a manner simulating $3.0 \mathrm{~mm}$ of the crestal bone loss. The jig carrying implant specimens was fixed onto the universal testing machine (Model 6025; Instron, Canton, MA, USA) in such a way that specimens were loaded with a $30^{\circ}$ oblique force recommended by the ISO 14801 standard. Off-axis loading was applied to the hemispherical cap of each implant by a flat indenter, ensuring the distance from the centre of the hemisphere cap to the cylinder surface (clamping plane) was $11.0 \mathrm{~mm}$. Therefore the moment arm was defined as $11.0 \mathrm{~mm} \times \sin 30^{\circ}(5.5 \mathrm{~mm})$. The ISO 14801 was followed by ensuring unconstrained movement of the loading member transverse to the loading direction. This was achieved by a socket fit joint between the loading member and the test machine structure. The joint was close to the load cell and was approximately $200 \mathrm{~mm}$ away from the lower end of the flat indenter. The abutments were tightened to implants with a torque value of $35 \mathrm{Ncm}$ using the BTG60CN-S torque gauge (Tohnichi, Tokyo, Japan). Ten minutes after the torque tightening, the test was carried out with a crosshead speed of $0.5 \mathrm{~mm} / \mathrm{min}$ until the implant fractured or exhibited a significant amount of plastic deformation. This kind of irreversible deformation is determined by fitting the load-displacement curves with the regression lines, and the force at which the load-displacement curve first deviates by $10 \%$ from the regression line will be recorded as an indicator for initiation of significant plastic deformation [12].

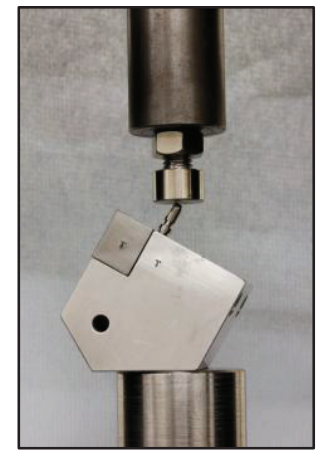


Figure 2 The compressive loading set-up with an implant specimen mounted on

\subsection{Statistical analysis \& fracture analysis}

Throughout the loading, the raw data of force-displacement values were recorded by the computer.

Data were subsequently used to determine the maximum load levels and create force-displacement curves. The mean and standard deviations of the fracture forces or the maximum deformation forces were determined, and the Tamhane's multiple comparison test was used to assess differences between groups. The level of significance was set as $\mathrm{P}<0.05$.

After the mechanical testing, macrofracture mode analysis was performed to identify different fracture modes for all the specimens. Further fractographic analysis was performed using a scanning electron microscope (SEM) (JEOL, JSM-7100F, Japan). For SEM evaluations implants were cleaned and dried. Digital images of the specimens were recorded at various magnifications to evaluate the fracture surfaces.

\subsection{Finite element analysis}

Numerical simulations were carried out to evaluate the mechanical properties of the implants with different abutment taper angles with particular reference to the implant-abutment connection area where fracture was expected to occur. Three dimensional models of the jig (an aluminum alloy cylinder and a stainless steel block) and implants were generated using the SolidWorks 2008 software (Dassault Systèmes SolidWorks Corp., Massachusetts, USA), which were the same as described in previous sections. The models were then transferred into the Ansys 13.0 software (ANSYS, Inc., Pennsylvania, USA) to generate 3D-FEA models, including six models of 3.5-6, 3.5-8, 3.5-10, 4-6, 4-8, and 4-10. Ten-node tetrahedral elements were used to generate the model mesh. Since this study was designed to evaluate the stress patterns, with particular reference to the connection region, simplifications were made to define the contacts (implant-abutment interface and implant-jig interface) as fully bonded interface. The boundary condition of total fixation on the nodes of the bottom face of the 
jig was chosen. The material properties of the models were assumed to be homogeneous, isotropic and linearly elastic, and the specific values were listed in Tab.1. A 200-N load, which was in the range of normal bite forces, was applied to the hemispherical dome of each implant with an inclination of $30^{\circ}$ from the implant long axis[13]. Distribution of von-Mises stresses in the implant neck area was observed.

Tab. 1 Mechanical properties of the finite element models

\begin{tabular}{lcc}
\hline Materials & Young's modulus $(\mathrm{GPa})$ & Poisson's ratio \\
\hline Ti-6Al-4V & 110 & 0.32 \\
Aluminum alloy & 79 & 0.33 \\
Stainless steel & 195 & 0.25 \\
\hline
\end{tabular}

\section{Results}

\subsection{The failure modes \& force-displacement curve}

The failure mode was almost identical in all specimens, including large deformations of the framework at the implant neck area, and two fracture surfaces: implant neck fracture and abutment screw fracture (Fig.3). The implant neck fracture took place in the neck region between the first and second threads which was flush with the surface of the aluminum cylinder. The fracture was large and accompanied with a strong bricking sound during the test. The abutment fracture was at the head of the screw just below the base of the abutment cone. In contrast, it was accompanied with a weak breaking sound. These two fracture events were recorded as sudden drops of loads by computer, and displayed as two obvious downward turning points in the force-displacement curve (Fig.4). The first turning point was at the top of the curve, which was defined as the failure force of implant specimens. And the second one was shortly after the first one and corresponded to abutment screw fracture. 


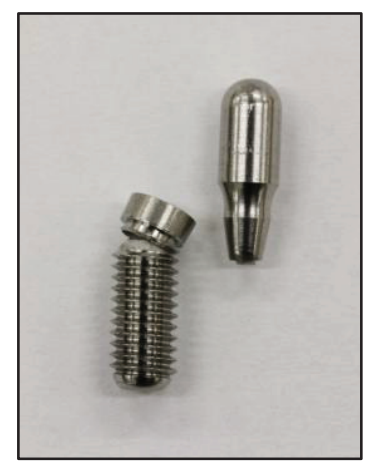

Figure 3 Photograph of a tested specimen showing fractures of the implant neck and abutment screw

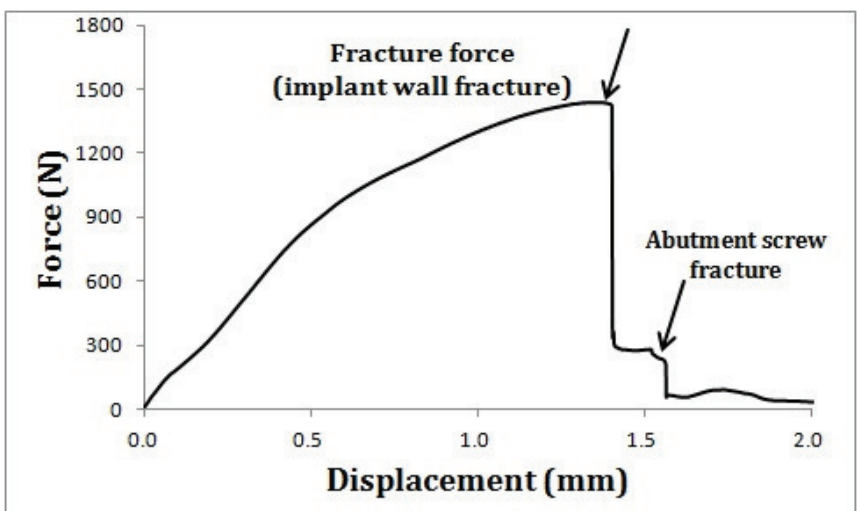

Figure 4 A representative load-displacement curve for implant specimens tested

\subsection{The maximum loads}

The maximum loads for all the six groups were summarized in figure 5, ranging from $1023.9 \mathrm{~N}$ (in group 4-6) to $1698.5 \mathrm{~N}$ (in group 3.5-10). In general, specimens of group 4-6 provided lower maximum loads than other 5 groups did. The value of every specimen in groups of $3.5-6,3.5-8,3.5-10$, and $4-10$ was larger than $1400 \mathrm{~N}$, and all the five specimens in group 3.5-8 had a value of more than $1600 \mathrm{~N}$.

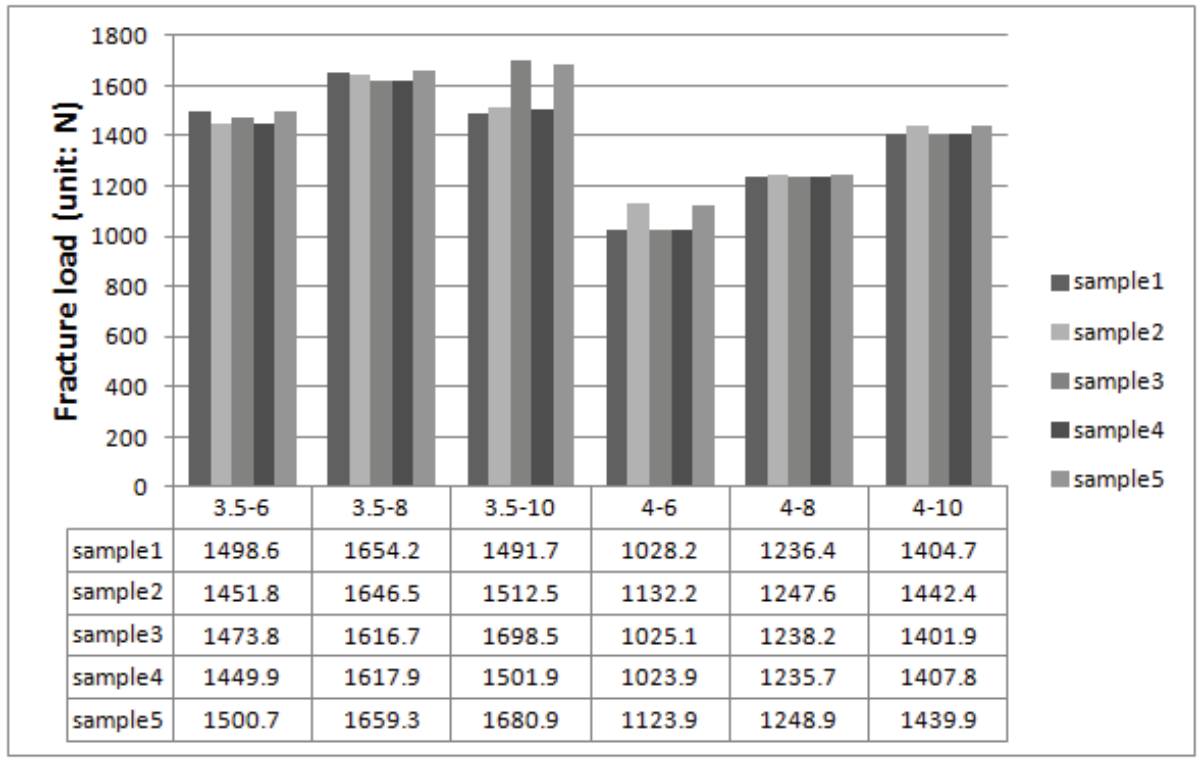




\subsection{Statistical and SEM analysis}

The mean maximum load, standard deviation, coefficient of variation, and bending moment values of all the specimens are shown in Tab.1. Implants in group 3.5-8 had the highest mean maximum load level of $1638.9 \mathrm{~N} \pm 20.3$, and the lowest value of $1066.7 \mathrm{~N} \pm 56.1$ was found in group 4-6. Groups of 3.5-6, 3.5-10, 4-8, and 4-10 provided values of $1475.0 \mathrm{~N} \pm 24.4,1577.1 \mathrm{~N} \pm 103.2,1241.4 \mathrm{~N} \pm 6.4$, and $1419.3 \mathrm{~N} \pm 20.0$, respectively.

Tab.2 Descriptive statistics of results for the six test groups

\begin{tabular}{lllllll}
\hline Specimen group & $3.5-6^{\mathrm{a}}$ & $3.5-8^{\mathrm{b}}$ & $3.5-10^{\mathrm{a}, \mathrm{b}}$ & $4^{\mathrm{b}} 6^{\mathrm{c}}$ & $4-8^{\mathrm{d}}$ & $4-10^{\mathrm{a}}$ \\
\hline Mean (N) & 1475.0 & 1638.9 & 1577.1 & 1066.7 & 1241.4 & 1419.3 \\
SD & 24.4 & 20.3 & 103.2 & 56.1 & 6.4 & 20.0 \\
CV & 0.0166 & 0.0124 & 0.0655 & 0.0526 & 0.0051 & 0.0141 \\
MBM (Nmm) & 8112.3 & 9014.1 & 8674.1 & 5866.6 & 6827.5 & 7806.4 \\
MDC (mm) & 1.5 & 2.0 & 2.5 & 1.3 & 1.5 & 1.6 \\
\hline SD= standard deviation, CV = Coefficient of variation, MBM=Mean Bending moments, MDC= Mean Displacement of Crosshead \\
\multicolumn{5}{l}{ Values denoted by the same superscripts do not differ with statistical significance. }
\end{tabular}

The results of the mean bending moment listed in Tab.2 were obtained by multiplying the mean maximum load and moment arm. In the loading set of this study, the moment arm was fixed as $5.5 \mathrm{~mm}$. Therefore, it was easier to get the mean bending moment values. Group 4-6 had the lowest mean maximum load value, which was significantly lower than that for other five groups, by the Tamhane's multiple comparison test $(P<0.05)$. The mean maximum load differences between group 4-8 and any other groups were statistically significant, with $\mathrm{P}<0.05$. There were no significant differences between the result of 3.5-10 and that of 3.5-6, and 3.5-8. Moreover, the result of 4-10 did not significantly differ from that of 3.5-6 and 3.5-10. The mean displacement values of the crosshead corresponding to the first load drop in Fig.4 recorded by the computer were shown in Tab.2. As the vertical displacements were from $1.3 \mathrm{~mm}$ to $2.5 \mathrm{~mm}$, there were only smaller lateral displacements of the specimens. Figure 6 is a typical SEM image of the fractured surface of one specimen, including implant neck wall fracture 
and failure surface of the abutment screw.
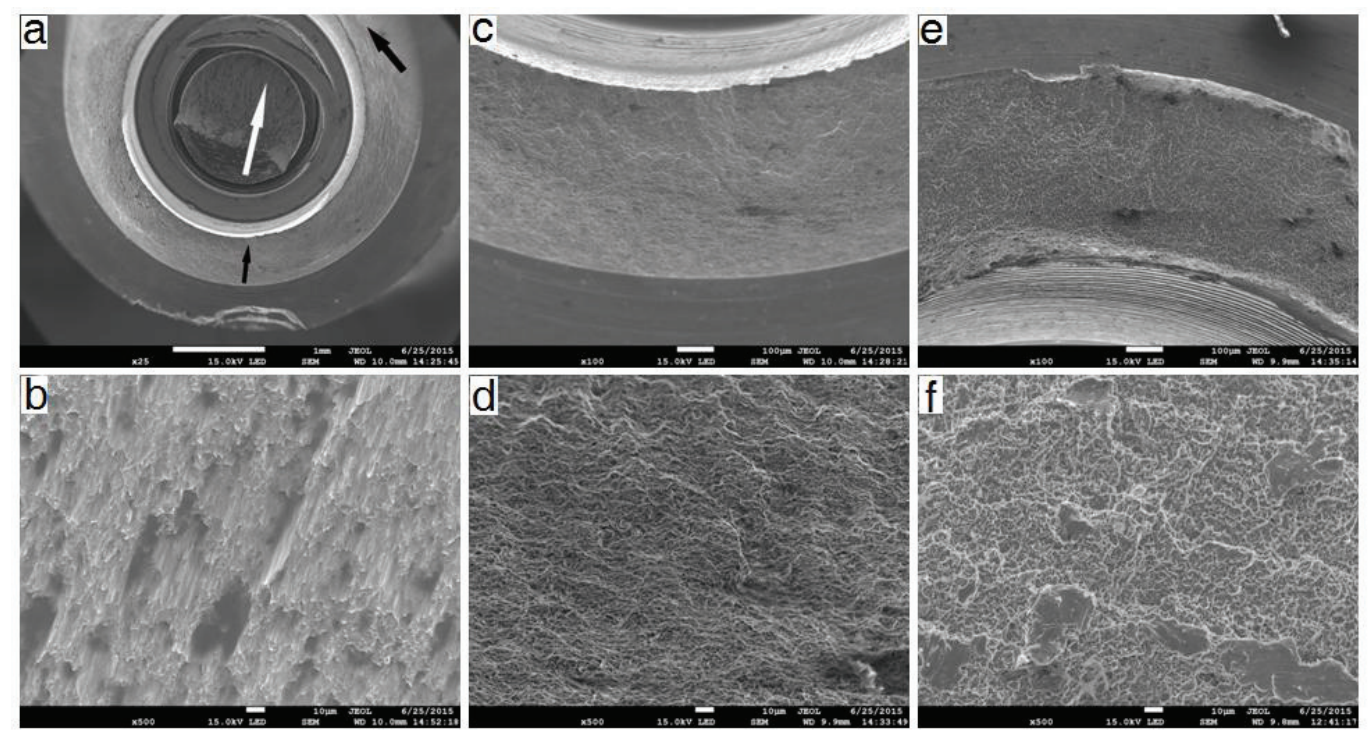

Figure 6. (a) is an overall view $(\times 25)$ of the fractured surfaces of one specimen, with the white arrow showing the fracture direction of the abutment screw. (b) is a higher magnitude $(\times 500)$ of fractured area in the middle of the abutment screw surface shown in $(a)$, with dimples being the characteristic of ductile failure. (c) shows the implant wall fracture profiles shown in (a) and indicated by the small black arrow, with dimples and microvoids indicating a slow ductile fracture . (e) shows the end area of implant wall fracture shown in (a) and indicated by the large black arrow with rapid fractures as shown by the shiny surfaces. (d) and (f) are the original magnification $\times 500$ of (c)and (e), respectively.

\subsection{D-FEA results}

Distribution of von-Mises stresses at the implant-abutment connection area was compared for implants with different abutment taper angles. For all the implants, the von-Mises stresses were concentrated at implant neck area around the first and second threads and the abutment connection part (Fig. 7). The greatest stress values were at the lingual (L) side of implant necks, and the values at the buccal $(B)$ side were a little bit smaller. Figure 8 shows the greatest stress values at the buccal and lingual sides of implant necks and the 4-6 model had the biggest stress values of $322.7 \mathrm{MPa}(\mathrm{B})$ and 368.4MPa ( $\mathrm{L}$ ) among the six models. In all the models, the biggest von-Mises stress values at the abutment connection part were remarkably lower than those at the implant neck area, and the values at the abutment screw were less than $50 \mathrm{MPa}$. 


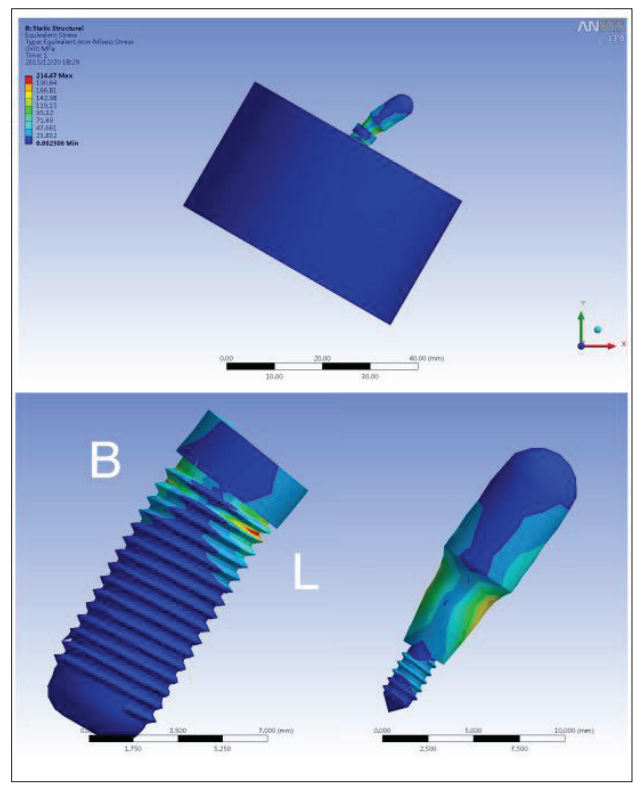

Figure 7 The top is one 3D-FEA model with enlargement of the implant deformation. The bottom shows the distribution of von-Mises stresses (MPa) in the implant-abutment connection area under the $200-\mathrm{N} 30^{\circ}$ off-axis loading. The stress concentration was located at the implant neck region between the first and second threads from the buccal (B) to the lingual (L) side (bottom left), and at the abutment connection part (bottom right).

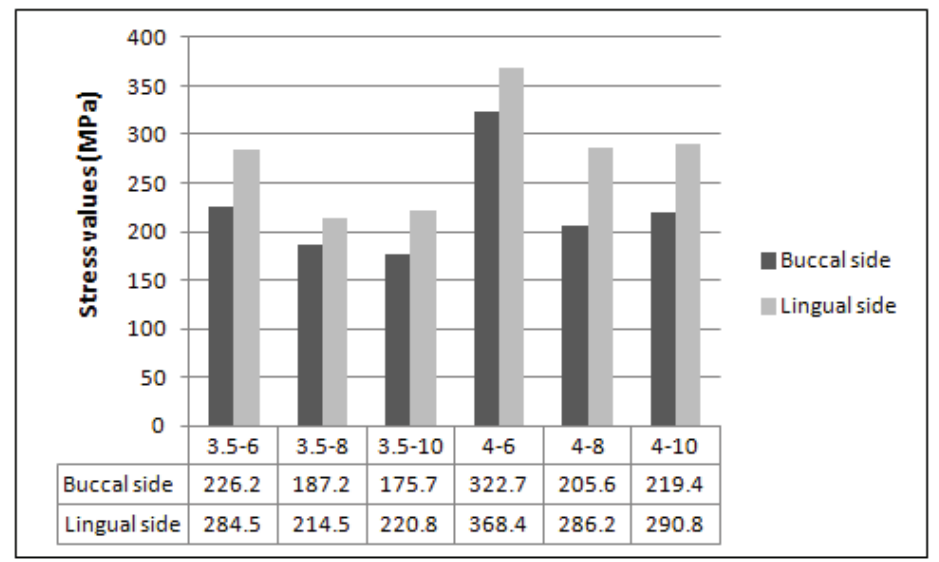

Figure 8 The greatest von-Mises stress values at the implant neck areas of the six models

\section{Discussion}

The experimental test is a reliable and useful method to determine the mechanical integrity for implant research and development purposes. It is repeatable and allows a comparative analysis of the mechanical response of different designs of implants undergoing the same loading and boundary conditions. Previous in vitro studies have evaluated effects of various parameters on implant static failure strength, which included implant or abutment dimensions, shapes, test protocol variables, 
materials, and implant-abutment interfaces. When it came to investigating effects of dimensions, materials and test protocol variables, usually the same implant system were chosen for the purpose of comparability [14-16]. As for comparisons of failure strength of implants with different implant-abutment interfaces, researchers had to use different implant systems, which varied not only in implant-abutment interfaces but also in shapes, dimensions, surface characteristics, and material properties [17]. Therefore, in most of the cases, the comparability was compromised and it was of an insufficient level to isolate influences of implant-abutment interfaces on fracture strength values precisely. For example, with the objective of comparing fracture strength of the implant-abutment connection of six established implant systems, investigators tested specimens from five different manufacturers, which were different not only in implant-abutment interface geometries but also different in diameter and morphological designs in their neck, body and threads [18]. As reported by Möllersten, these studies could not find the exact influences of implant-abutment connections on implant fracture strengths, but rather compare the mechanical behavior of the whole systems [7]. However, in this study good comparability between different groups was guaranteed by custom-manufacturing implants with identical parameters of implant diameter, implant shapes, material, and abutment connection depth.

In the present study, the mean values of maximum load were from $1066.7 \mathrm{~N} \pm 56.1$ to $1638.9 \mathrm{~N} \pm 20.3$. And the mean maximum bending moments for the six groups ranged from $5866.6 \mathrm{Nmm}$ to 9014.1 $\mathrm{Nmm}$. The present results of the maximum forces are in the similar ranges of previously published studies of static tests using implants with diameter of $5.0 \mathrm{~mm}$ but different implant structures. Shemtov-Yona et al. reported the maximum fracture forces of their implant system in a range of $1400-1700 \mathrm{~N}$, with a mean of $1584 \mathrm{~N} \pm 115$ [15]. Steinebrunner and colleagues tested four commercial 
implant systems with the median fracture strengths varying from $782 \mathrm{~N}$ to $1542 \mathrm{~N}$ [18]. However, our results compare favorably with those previously reported by Norton [19], who found the mean maximum bending moment of $5507 \mathrm{Nmm}($ load $=220 \mathrm{~N})$ and $3269 \mathrm{Nmm}(\mathrm{load}=131 \mathrm{~N})$ were recorded for the Astra ( $11^{\circ}$ taper angle) and ITI ( $8^{\circ}$ taper angle) TIS-type implants, respectively. This is likely to be the result of three factors. One was that Norton used the 3-point bending test method which applied loads at an angle of $90^{\circ}$. At this angle, implants were prone to be fractured with lower load levels. Furthermore, all implant components in Norton's study were manufactured from commercially pure titanium, which had inferior mechanical strength to Ti-6Al-4V alloy used in this study. Moreover, implants tested in our study had a diameter of $5.0 \mathrm{~mm}$, which was larger than that of Astra $(4.5 \mathrm{~mm})$ and ITI (4.1mm). Norton demonstrated Astra implant systems had a better resistance to 3-point bending loadings than ITI ones. However, there was less comparability in terms of implant shapes, dimensions, and implant-abutment connections of the two tested systems, which are the factors determining implant mechanical strengths $[20,21]$. Therefore, it is not possible to find how these variables affect implant fracture strengths, much less the exact effect of connection design or taper angles on the fracture resistance. The present study for the first time studied relationships between taper angles and implant static strength, with good intergroup comparability by using identical implant designs, diameters, and materials.

In this study, all implants were statically compressed under $30^{\circ}$ off-axis loadings until fracture occurred. The failure mode was almost identical in all specimens, including two fracture surfaces: implant neck fracture and abutment screw fracture. And this failure mode was similar to that of ITI implants with $8^{\circ}$ TIS-connection designs reported in one in vitro study [22]. The SEM analysis showed that the mode of fracture for abutment screws was ductile, characterized by rough and dull surfaces 
with numerous large dimples (Fig. 6 b). Since the circular abutment screw fracture had two facets which met at an angle, their junction appeared in a rung shape in the SEM images. The abutment screw was in a small diameter of $2.0 \mathrm{~mm}$ and it fractured in much lower loads than implant wall, therefore its failure corresponded to the second sharp drop in the load-displacement curve (Fig.4). Implant wall fracture developed at the thread bottom of buccal side of implant neck (indicated by small black arrow) and advanced along thread spiral line to the lingual side (indicated by large black arrow), with fracture direction being marked by the white arrow in Fig.6. Implant wall fracture started with a slow ductile fracture with dimples and microvoids (Fig.6 c \& d) and ended with rapid fractures as shown by the shiny surfaces (Fig.6 e \& f). These SEM findings are consistent with the results reported by Apicella and Chan et al $[23,24]$.

The implant neck fracture took place in the neck region, and was recorded as the first turning point at the top of the force-displacement curve, which was defined as the failure force. Therefore, the fracture resistance of the whole specimen was determined by strength in the area of implant neck under present loading settings. More specifically, implant fracture strength was closely correlated to wall thickness in the implant neck area, which varied among groups with different abutment taper angles in this study (Fig.1). This agrees with the experimental results of one static test, which confirmed that the triangular connection design of the NobelSpeedy Replace $3.5 \mathrm{~mm}$ implant system compromised its neck wall thickness, and made it more predisposed to fracture than the thicker continuous wall in the other systems [21]. In addition, it is consistent with numerical studies. van Staden and colleagues investigated stresses of dental implants with different wall thicknesses using FEA method, which demonstrated that the implant wall thickness had significant influence to the stress magnitude and distribution pattern within the implant and reduced wall thickness would result in higher stress 
magnitudes [25]. In another FEA study, the authors found that, for the implants with the same diameter, reducing the abutment diameter could decrease the bone stress significantly under loading, which might be due to the fact that a small abutment diameter provides a thicker fixture wall for transmitting stresses than a larger abutment diameter. The higher thickness of fixture wall seems to provide the benefit of reducing the stress in the implant, leading to lower stresses in the bone [26].

According to the engineering principle on fracture strength of cylinders interpreted by Misch, increasing wall thickness of two-piece implants will significantly increase implant fracture resistance [20]. This fact is exemplified in the present study by the findings that groups with abutments in 3.5mm-diameter showed higher mean fracture strengths compared with the groups with abutments in 4.0mm-diameter. Obviously, the wall thicknesses in former groups were larger than those of latter ones. Furthermore, the abovementioned mechanical principle could be verified by comparing the mean failure strength of groups with $4.0 \mathrm{~mm}$-diameter abutments. The minimum wall thickness in the implant neck area increased from $0.34 \mathrm{~mm}(4-6)$ to $0.41 \mathrm{~mm}(4-8)$ and $0.48 \mathrm{~mm}(4-10)$, as abutment cone taper increased from $6^{\circ}$ to $8^{\circ}$ and $10^{\circ}$. The mean fracture strength resulted from these minor changes of wall thickness increased gradually from $1066.7 \mathrm{~N}$ to $1241.4 \mathrm{~N}$ and $1419.3 \mathrm{~N}$, respectively. Compared with the $6^{\circ}$ taper, $8^{\circ}$ and $10^{\circ}$ taper angles increased the mean maximum force by $16.4 \%$ and $33.1 \%$, respectively.

Dental implants used in this study were not of regular hollow cylinder design but complicated shapes. In addition, taper enlargement would make wall thickness larger, and result in dimension and size changes of the abutment itself as well. Accordingly, the abovementioned engineering principle is not necessarily applicable in all implant specimens, and it should be used with caution, especially when minor changes happened within a small dimension of $5.0 \mathrm{~mm}$. It would be reasonable to expect that as 
wall thickness became larger and larger, implant fracture strength could not increase continuously without limitations. In fact, it would inevitably enter into a plateau, where extra wall thickness enhancement would not strengthen implants more. Accordingly, as for groups with $3.5 \mathrm{~mm}$-diameter abutments, when the minimum wall thickness in the implant neck area increased from $0.59 \mathrm{~mm}(3.5-6)$ to $0.66 \mathrm{~mm}(3.5-8)$ resulted from taper angle enlargement from $6^{\circ}$ to $8^{\circ}$, the increasing rate of the mean fracture force was $11.1 \%$. Then, as compared to the $8^{\circ}$ taper group, the mean fracture resistance of $10^{\circ}$ taper specimens did not go to higher level but dropped slightly, indicating that a plateau has been reached.

In all the FEA models, a $30^{\circ}$ off-axis load was applied to implants, which produced a force moment bending implants to their lingual side. Therefore, the stress concentration was at neck areas between the first and second threads, and the greatest stress levels at the lingual side were larger than those at the buccal side. These results agree with the FEA findings reported by Sannino et al [27], and verified by the present static tests in which implants' fractures occurred at their neck areas. The present numerical results showed that stress values varied in implants with different abutment taper angles. The $4 \mathrm{~mm}$ abutment diameter implants had higher stress values than their $3.5 \mathrm{~mm}$ counterparts did in implant neck areas. For $4.0 \mathrm{~mm}$ abutment diameter implants, stress values of 4-6 were larger than those of $4-8$ and $4-10$, and there was no notable difference between the latter two models. And it was also true of the $3.5 \mathrm{~mm}$ counterparts. From the mechanical perspective, the thinner implant wall thickness meant less material volume at the implant wall area, which performed less well in dispersing stresses and caused greater stress concentration [25]. Accordingly, these stress differences could be accounted for by the variations of the implant neck wall thickness, which changed with the abutment taper angles. Therefore, these stress results confirmed the findings of the present mechanical tests, 
where implant specimens with thinner implant wall thickness had poorer fracture strength. And moreover, the variation tendencies of stress values of implants with different abutment taper angles were consistent with the variation trends of implant fracture loads obtained from the static tests.

In addition to the implant fracture strength, the efficiency of TIS-type connection is another important mechanical configuration for an implant system, which is defined as the ratio of the loosening torque (abutment removal torque) to the tightening torque (abutment screwing in torque). High efficiency means the connection performs well in preventing abutment screw loosening. As calculated by Bozkaya et al [9], the efficiency is negatively correlated to the taper angle, depending on the value of the friction coefficient. Accordingly, when to determine the idea taper angle for developing a new implant system of the TIS-type connection with proper mechanical configurations, the designers should achieve a balance between the increasing effects of taper angle for implant strength and the decreasing effects of taper angle for the torque efficiency.

It is evident that the results of the present study are of significance to researchers in implant design and manufacturing. Moreover, they are useful for clinicians. According to Allum and co-authors [28], most of the implant manufacturers keep the implant mechanical strength information unpublished, which is largely unavailable to clinical practitioners. Therefore the results of this study break down the barriers, and provide foundation for making a choice from TIS-connection implant systems with different taper angles by clinical practitioners, when superior implant strength is preferred to withstand higher masticatory forces in posterior region restorations or in patients with bruxism. In addition, clinicians can use the data obtained by this research to make a judgment on the mechanical qualities of implants claimed by manufacturers, who might exaggerate their products' mechanical properties for the purpose of commercial interests. 


\section{Conclusion}

This paper presents the statically tested results of effects of abutment taper angles on fracture strengths of dental implants, and the 3D-FEA numerical results of stress state of implant-abutment connection areas as a function of different abutment taper angles. Within the limitations of this research, the following conclusions can be drawn:

1) The increases of taper angle could significantly increase implant fracture resistance in most cases established in the study, which is due to the increased implant wall thickness in the taper part resulted from the taper angle enlargement.

2) The increasing effects are notable when thin implant wall is present to accommodate wide abutments.

3) As for implants with small diameter abutments, the increasing rate of implant fracture resistances is relatively low or will level off for the further increases of the taper angle.

4) The 3D-FEA stress results confirm the findings of the mechanical tests by showing that stress values varied in implants with different abutment taper angles, and the stress variation tendencies of implants with different abutment taper angles were consistent with the variation trends of implant fracture strengths obtained from the static tests.

\section{Acknowledgments}

The authors would like to acknowledge Mr. C.Y. Tang and P. Haynes for their valued technical assistance with the specimen tests, and thank Prof. K.F. Wang for his help in statistical data analysis.

\section{References}

1. B. Rangert, T. Jemt, L. Jörneus, Forces and moments on Branemark implants, Int J Oral Maxillofac Implants. 
4(1989)241-247.

2. L. Jörnéus, T. Jemt, L. Carlsson, Loads and designs of screw joints for single crowns supported by osseointegrated implants, Int J Oral Maxillofac Implants. 7(1992)353-359.

3. G.A. Zarb, A. Schmitt, The longitudinal clinical effectiveness of osseointegrated dental implants: The Toronto study, Part III: Problems and complications encountered, J Prosthet Dent. 64(1990)185-194.

4. T. Jemt, B. Lindén, U. Lekholm, Failures and complications in 127 consecutively placed fixed partial prostheses supported by Brånemark implants: from prosthetic treatment to first annual checkup, Int J Oral Maxillofac Implants. $7(1992) 40-44$.

5. T. Jemt, W.R. Laney, D. Harris, P.J. Henry, P.H. Krogh Jr, G. Polizzi, G.A. Zarb, I. Herrmann, Osseointegrated implants for single tooth replacement: a 1-year report from a multicenter prospective study, Int J Oral Maxillofac Implants. 6(1991)29-36.

6. W. Becker, B.E. Becker, Replacement of maxillary and mandibular molars with single endosseous implant restorations: a retrospective study, J Prosthet Dent. 74(1995)51-55.

7. L. Möllersten, P. Lockowandt, L.A. Lindén, Comparison of strength and failure mode of seven implant systems: an in vitro test, J Prosthet Dent. 78(1997)582-591.

8. G.E. Romanos, G.H. Nentwig, Single molar replacement with a progressive thread design implant system: a retrospective clinical report, Int J Oral Maxillofac Implants. 15(2000)831-836.

9. D. Bozkaya, S. Müftü, Mechanics of the taper integrated screwed-in (TIS) abutments used in dental implants, J Biomech. 38(2005)87-97.

10. Y. Maeda, T. Satoh, M. Sogo, In vitro differences of stress concentrations for internal and external hex implant-abutment connections: a short communication, J Oral Rehabil. 33(2006)75-78.

11. P.P. Binon, Implants and components: entering the new millennium, Int J Oral Maxillofac Implants. 15(2000) 76-94.

12. S. Dittmer, M.P. Dittmer, P. Kohorst, M. Jendras, L. Borchers, M. Stiesch, Effect of implant-abutment connection design on load bearing capacity and failure mode of implants, J Prosthodont. 20(2011)510-516.

13. J. Aguirrebeitia, M. Abasolo, J. Vallejo, R. Ansola, Dental implants with conical implant-abutment interface: influence of the conical angle difference on the mechanical behavior of the implant, Int J Oral Maxillofac Implants. 28(2013)e72-82.

14. C.K. Lee, M. Karl, J.R. Kelly, Evaluation of test protocol variables for dental implant fatigue research, Dent Mater. 25(2009)1419-1425.

15. K. Shemtov-Yona, D. Rittel, L. Levin, E.E. Machtei, Effect of dental implant diameter on fatigue performance, Part I: mechanical behavior, Clin Implant Dent Relat Res. 16(2014)172-177.

16. C.F. Wang, H.L. Huang, D.J. Lin, Y.W. Shen, L.J. Fuh, J.T. Hsu, Comparisons of maximum deformation and failure forces at the implant-abutment interface of titanium implants between titanium-alloy and zirconia abutments with two levels of marginal bone loss, Biomed Eng Online.12(2013)45.

17. C.N. Elias, D.J. Fernandes, C.R. Resende, J. Roestel, Mechanical properties, surface morphology and stability of a modified commercially pure high strength titanium alloy for dental implants, Dent Mater. 31(2015)e1-e13.

18. L. Steinebrunner, S. Wolfart, K. Ludwig, M. Kern, Implant-abutment interface design affects fatigue and fracture strength of implants, Clin Oral Implants Res.19(2008)1276-1284.

19. M.R. Norton, In vitro evaluation of the strength of the conical implant-to-abutment joint in two commercially available implant systems, J Prosthet Dent. 83(2000)567-571.

20. C.E. Misch, H.L. Wang, C.M. Misch, M. Sharawy, J. Lemons, K.W. Judy, Rationale for the application of immediate load in implant dentistry, part II, Implant Dent. 13(2004)310-321.

21. A.Y. Imam, A. Moshaverinia, E.A. McGlumphy, Implant-abutment interface: a comparison of the ultimate force to failure among narrow-diameter implant systems, J Prosthet Dent.112(2014)136-142. 
22. J. Perriard, W.A. Wiskott, A. Mellal, S.S. Scherrer, J. Botsis, U.C. Belser, Fatigue resistance of ITI implant-abutment connectors - a comparison of the standard cone with a novel internally keyed design, Clin Oral Implants Res.13(2002)542-549.

23. D. Apicella, M. Veltri, P. Balleri, A. Apicella, M. Ferrari, Influence of abutment material on the fracture strength and failure modes of abutment-fixture assemblies when loaded in a bio-faithful simulation, Clin Oral Implants Res. 22(2011)182-188.

24. H.L. Chan, W.S. Oh, H.S. Ong, J.H. Fu, M.Steigmann, M.Sierraalta, H.L.Wang, Impact of implantoplasty on strength of the implant-abutment complex, Int J Oral Maxillofac Implants. 28(2013)1530-1535.

25. R.C. van Staden, H. Guan, Y.C. Loo, N.W. Johnson, N. Meredith, Stress evaluation of dental implant wall thickness using numerical techniques, Applied Osseointegration Research. 6(2008)39-47.

26. C.M. Chu, H.L. Huang, J.T. Hsu, L.J. Fuh, Influences of internal tapered abutment designs on bone stresses around a dental implant: three-dimensional finite element method with statistical evaluation, J Periodontol. 83(2012) $111-118$

27. G. Sannino, A. Barlattani, Mechanical evaluation of an implant-abutment self-locking taper connection: finite element analysis and experimental tests, Int J Oral Maxillofac Implants. 28(2013)e17-26.

28. S.R. Allum, R.A. Tomlinson, R. Joshi, The impact of loads on standard diameter, small diameter and mini implants: a comparative laboratory study, Clin Oral Implants Res.19(2008)553-559.

\section{Figure Captions}

Figure 1. The engineering drawing of the implant specimens tested in this study

Figure 2. The compressive loading set-up with an implant specimen mounted on

Figure 3. Photograph of a tested specimen showing fractures of the implant neck and abutment screw Figure 4. A representative load-displacement curve for implant specimens tested

Figure 5. Values of maximum loads for the six test groups

Figure 6. (a) is an overall view $(\times 25)$ of the fractured surfaces of one specimen, with the white arrow showing the fracture direction of the abutment screw. (b) is a higher magnitude $(\times 500)$ of fractured area in the middle of the abutment screw surface shown in (a), with dimples being the characteristic of ductile failure. (c) shows the implant wall fracture profiles shown in (a) and indicated by the small black arrow, with dimples and microvoids indicating a slow ductile fracture . (e) shows the end area of implant wall fracture shown in (a) and indicated by the large black arrow with rapid fractures as shown by the shiny surfaces. (d) and (f) are the original magnification $\times 500$ of (c)and (e), respectively.

Figure 7. The top is one 3D-FEA model with enlargement of the implant deformation. The bottom shows the distribution of von-Mises stresses (MPa) in the implant-abutment connection area under the 200-N $30^{\circ}$ off-axis loading. The stress concentration was located at the implant neck region between the first and second threads from the buccal $(B)$ to the lingual $(L)$ side (bottom left), and at the abutment connection part (bottom right).

Figure 8. The greatest von-Mises stress values at the implant neck areas of the six models 
$a=a b u t m e n t$ diameter $(3.5 \mathrm{~mm}$ and $4.0 \mathrm{~mm})$ $b=$ the minimum wall thickness $\theta=$ taper angle $(6,8$ and 10 degrees)

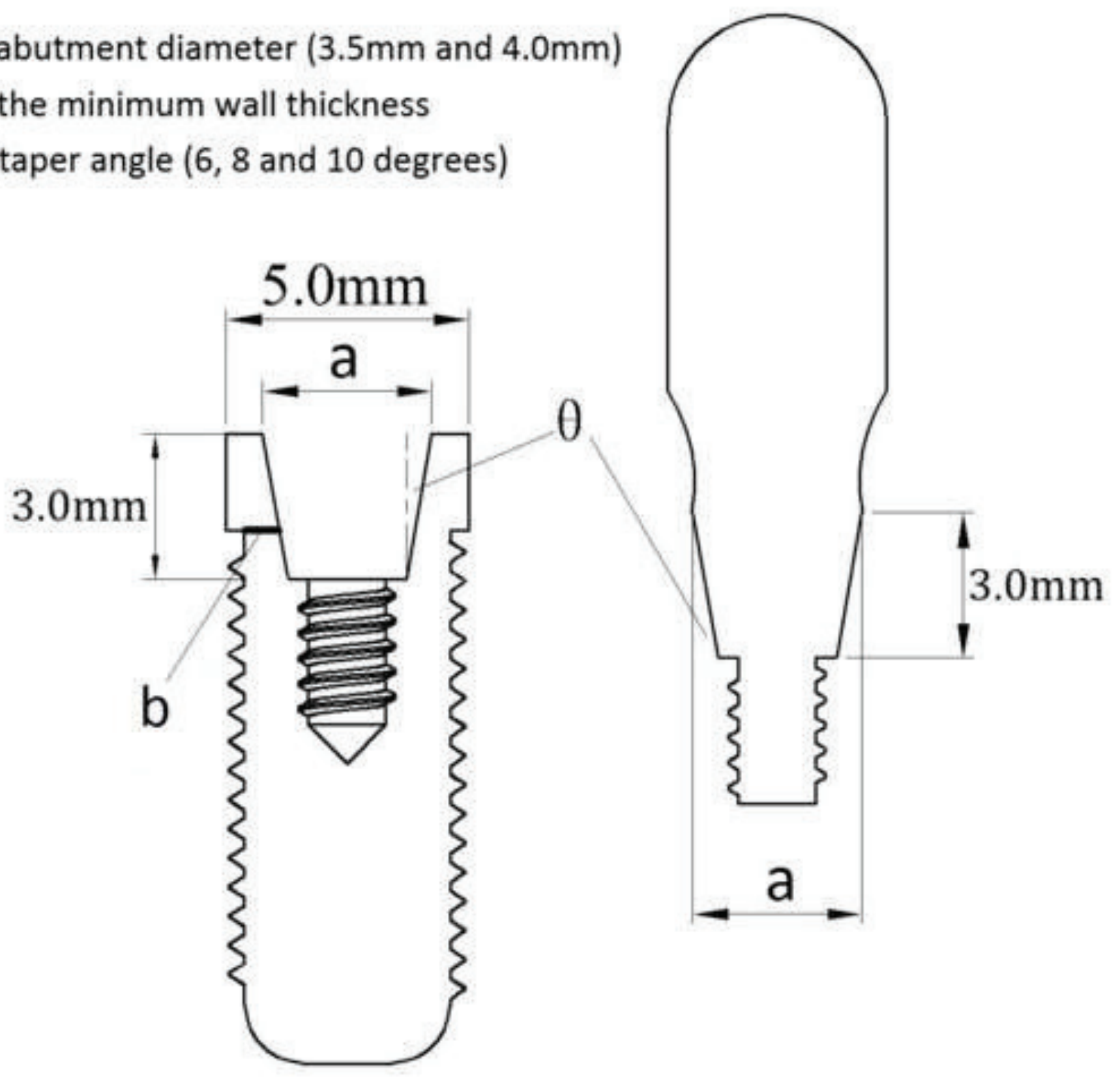




\section{Figure 2}

Click here to download high resolution image

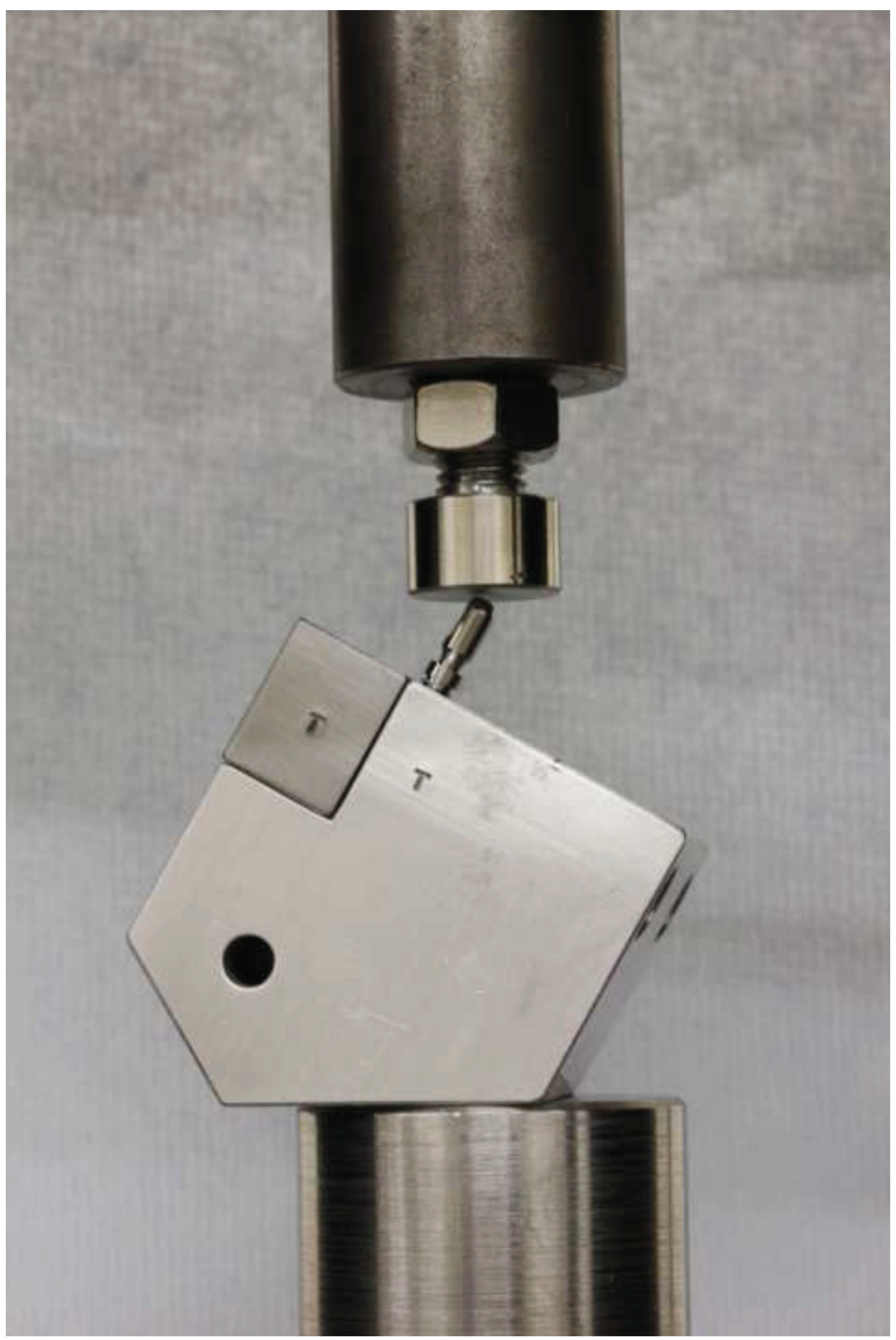


Click here to download high resolution image
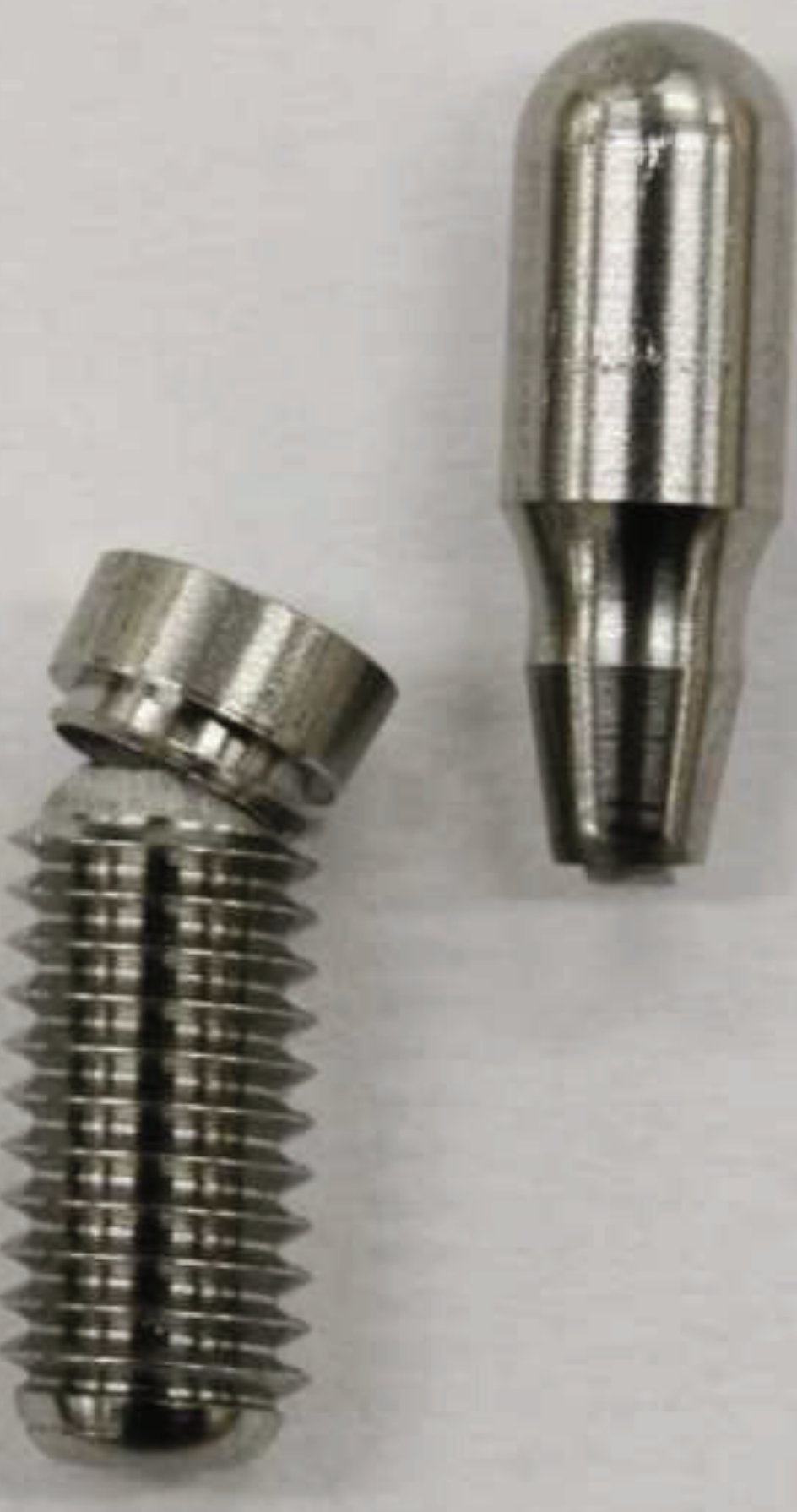


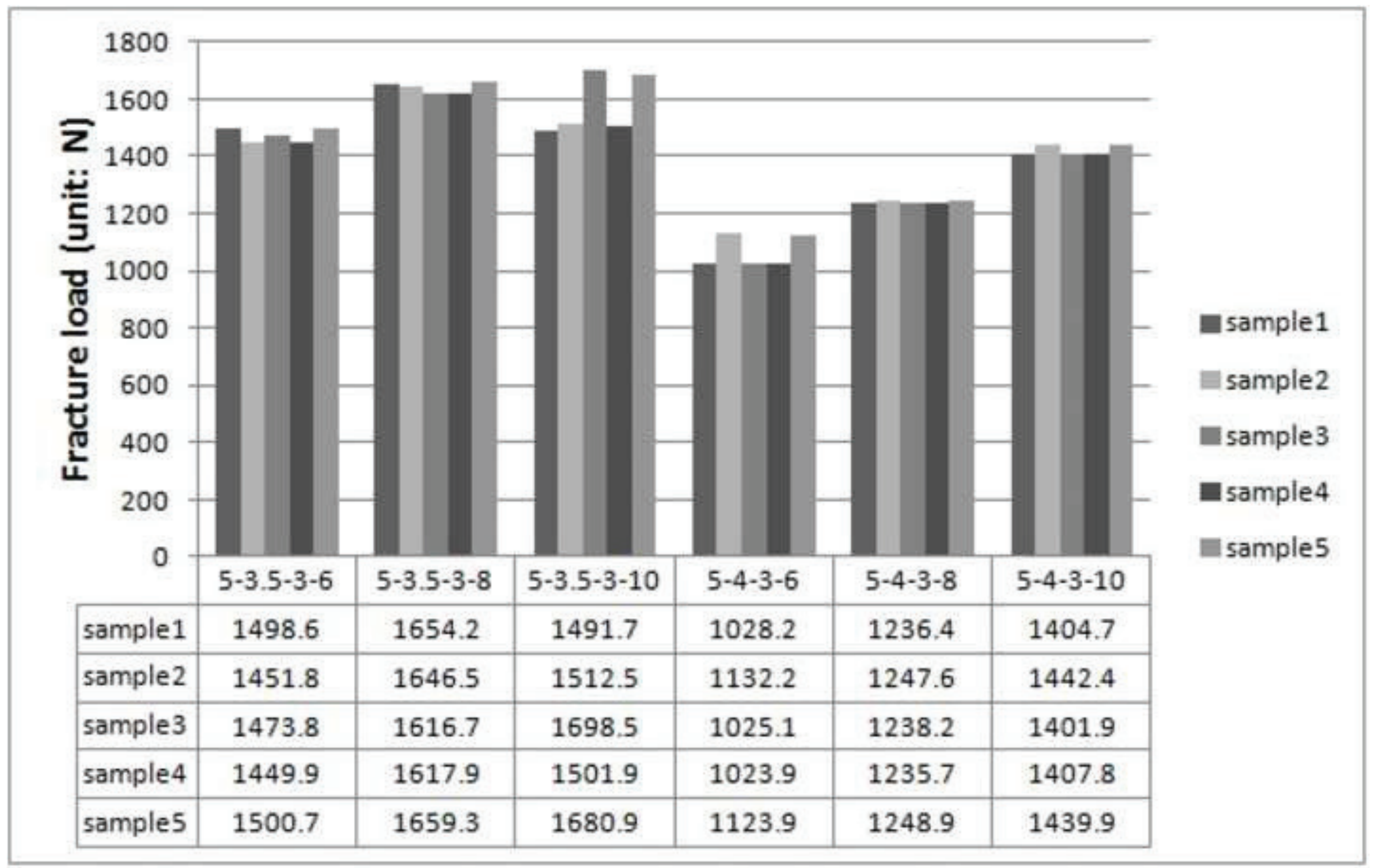




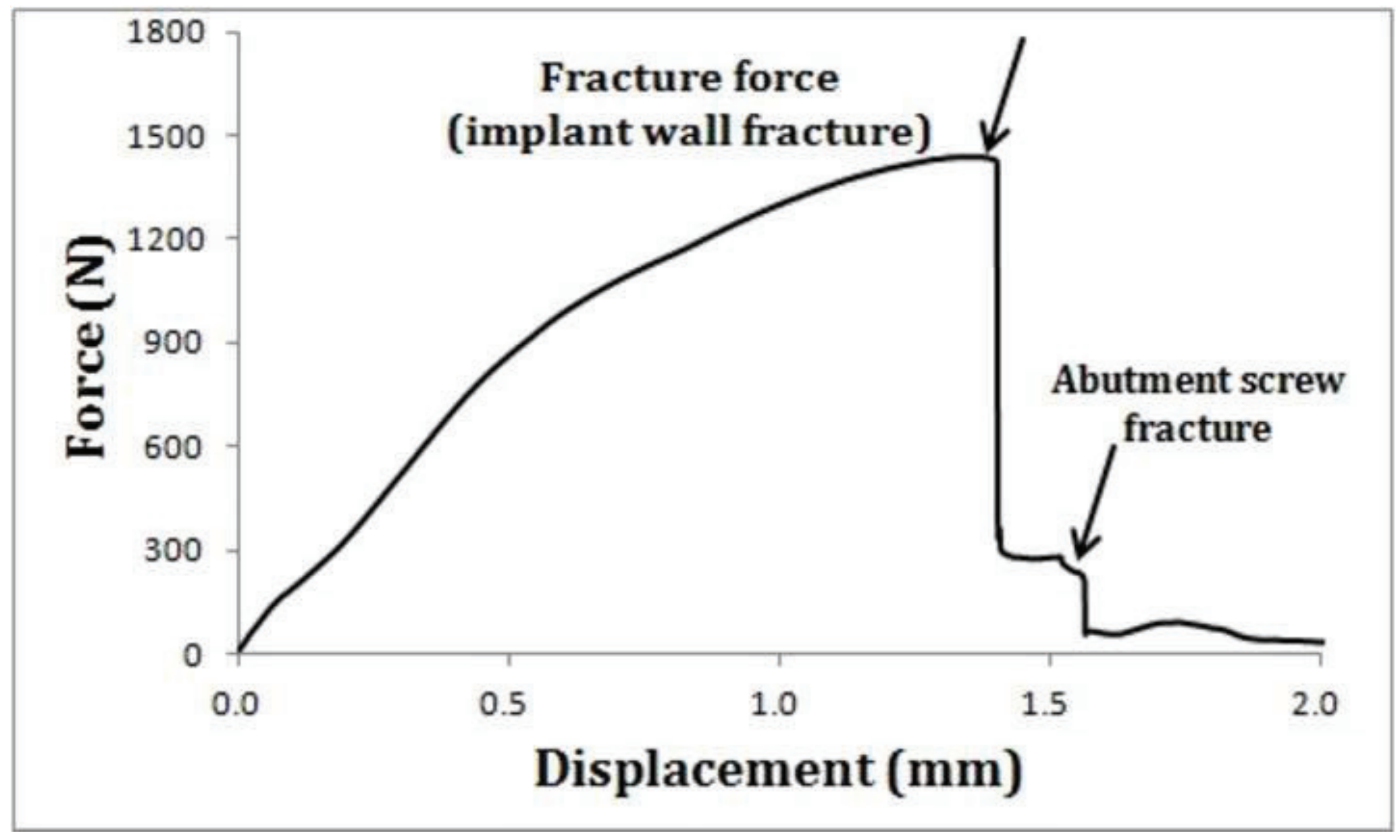


Click here to download high resolution image
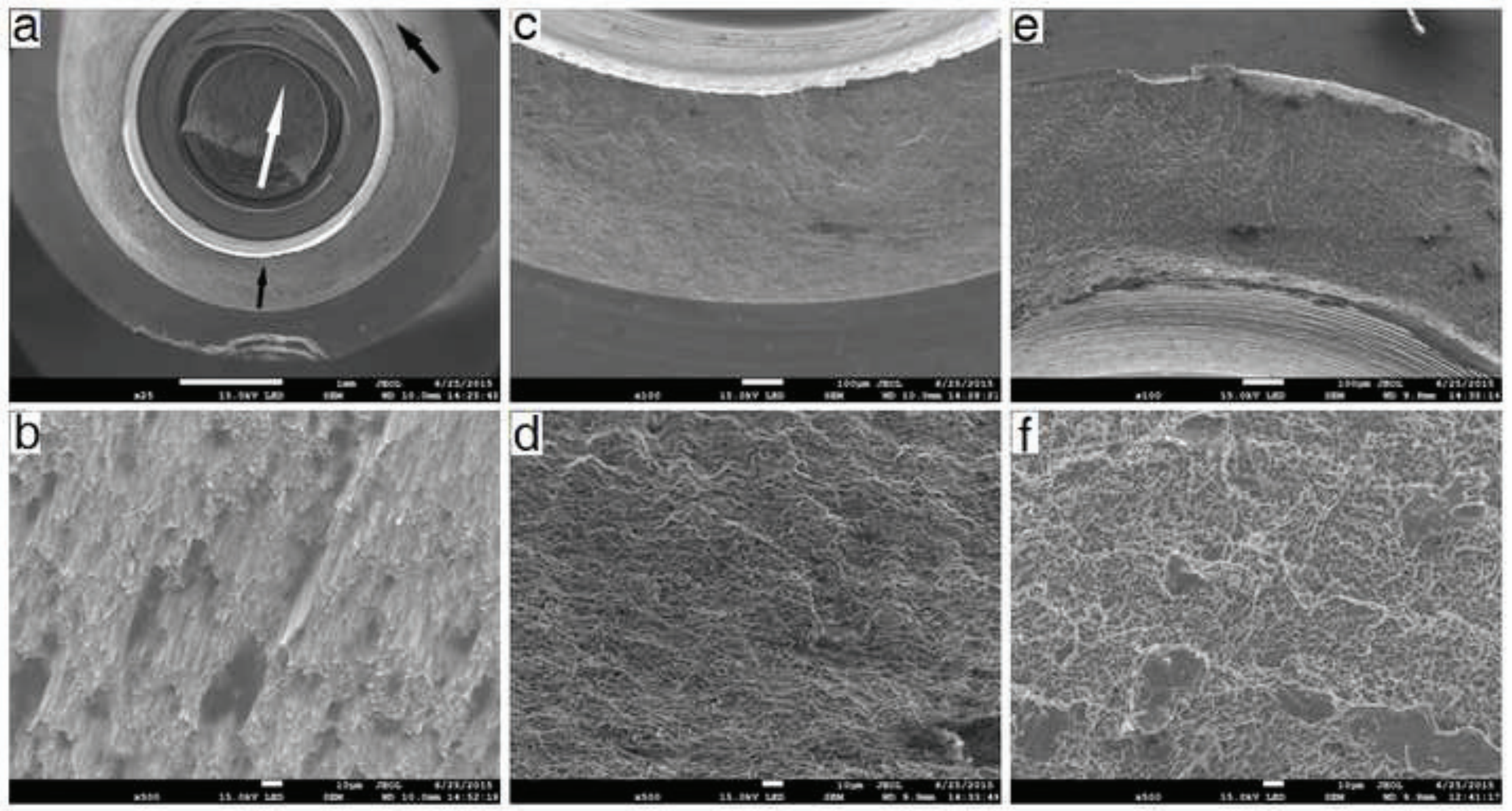
Figure 7
Click here to download high resolution image
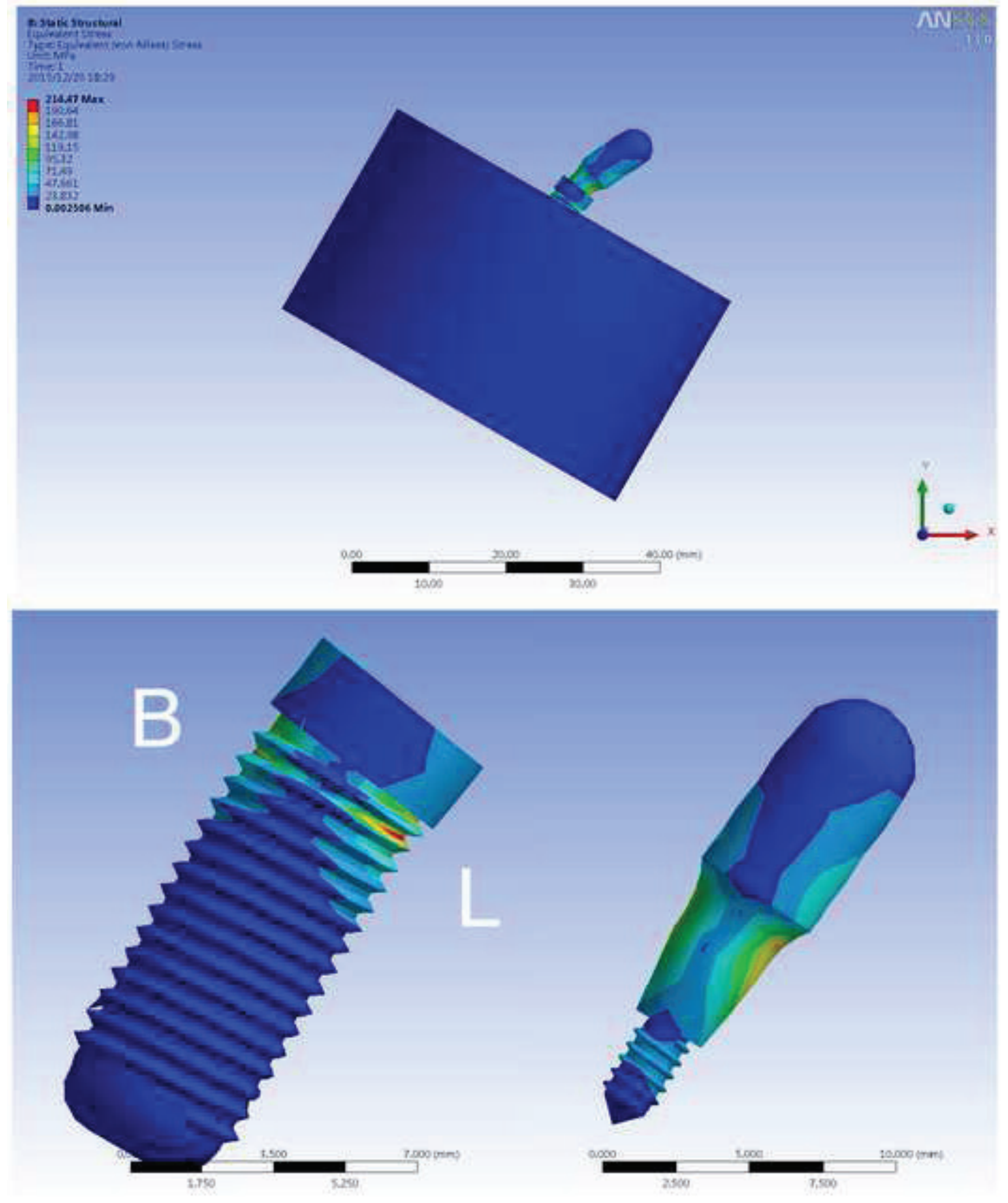


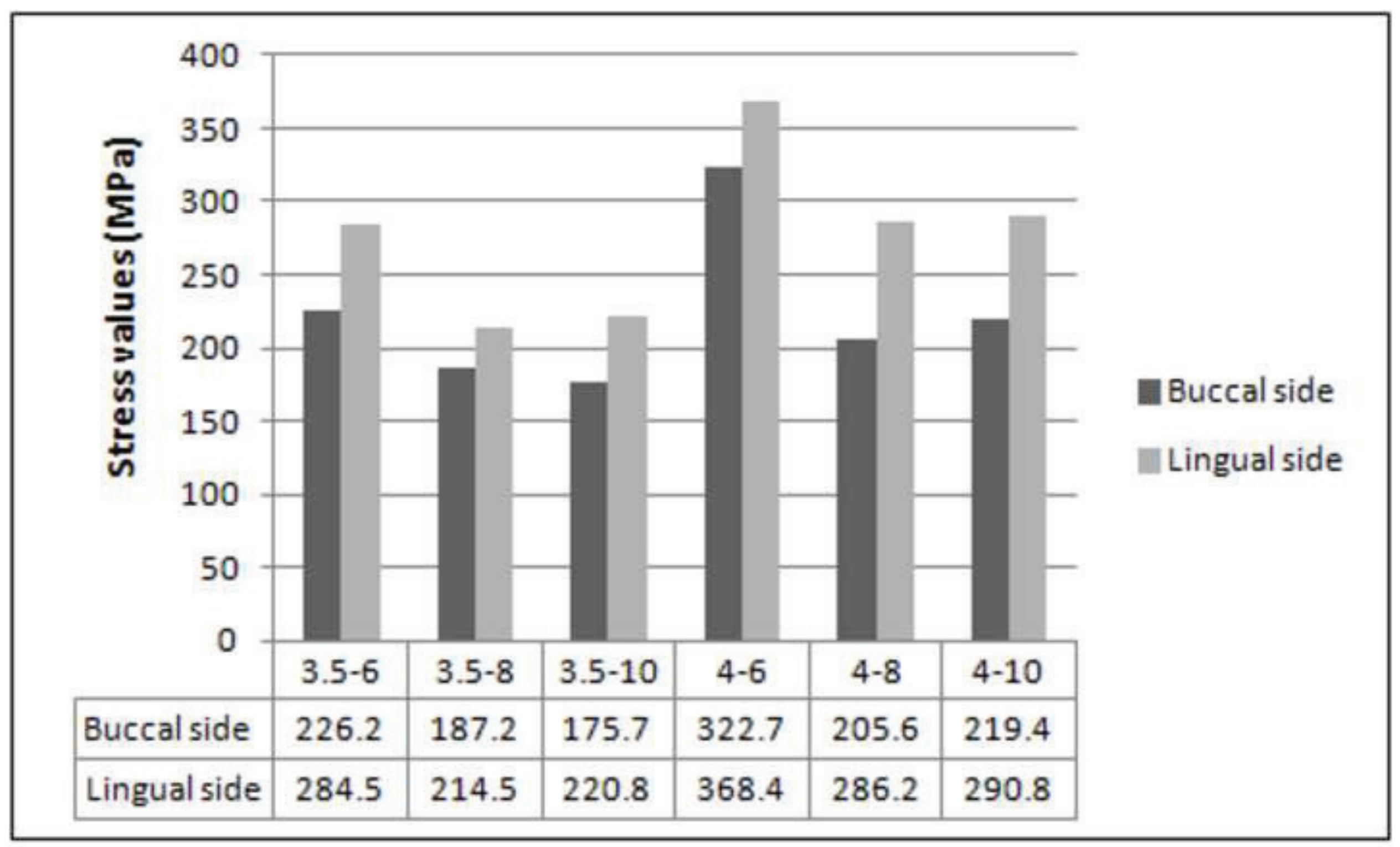




\section{Tables}

Table. 1 Mechanical properties of the finite element models

\begin{tabular}{lcc}
\hline Materials & Young's modulus $(\mathrm{GPa})$ & Poisson's ratio \\
\hline Ti-6Al-4V & 110 & 0.32 \\
Aluminum alloy & 79 & 0.33 \\
Stainless steel & 195 & 0.25 \\
\hline
\end{tabular}

Table.2 Descriptive statistics of results for the six test groups

\begin{tabular}{lllllll}
\hline Specimen group & $3.5-6^{\mathrm{a}}$ & $3.5-8^{\mathrm{b}}$ & $3.5-10^{\mathrm{a}, \mathrm{b}}$ & $4-6^{\mathrm{C}}$ & $4-8^{\mathrm{d}}$ & $4-10^{\mathrm{a}}$ \\
\hline Mean (N) & 1475.0 & 1638.9 & 1577.1 & 1066.7 & 1241.4 & 1419.3 \\
SD & 24.4 & 20.3 & 103.2 & 56.1 & 6.4 & 20.0 \\
$\mathrm{CV}$ & 0.0166 & 0.0124 & 0.0655 & 0.0526 & 0.0051 & 0.0141 \\
MBM (Nmm) & 8112.3 & 9014.1 & 8674.1 & 5866.6 & 6827.5 & 7806.4 \\
MDC (mm) & 1.5 & 2.0 & 2.5 & 1.3 & 1.5 & 1.6 \\
\hline SD= standard deviation, CV = Coefficient of variation, MBM=Mean Bending moments, MDC= Mean Displacement of Crosshead \\
\multicolumn{7}{r}{ Values denoted by the same superscripts do not differ with statistical significance. }
\end{tabular}

